\title{
Estudo preliminar sobre a relação entre o comprimento total e o desenvolvimento sexual em fêmeas de Psammobatis extenta (Garman, 1913)*
}

\section{Preliminary report on the relationship between total length and sexual development in Psammobatis extenta (Garman, 1913) females}

\section{Estudio preliminar sobre la relación entre la largura total y el desarrollo sexual de las hembras del Psammobatis extenta (Garman, 1913)}

\author{
André Luís da Silva Casas; ${ }^{1}$ Carlo Magenta da Cunha; ${ }^{2}$ Arani Nanci Bomfim Mariana ${ }^{3}$ \\ Departamento de Cirurgia da Faculdade de Medicina Veterinária e Zootecnia da Universidade de São Paulo \\ (FMVZ/USP). São Paulo, SP, Brasil
}

\section{Resumo}

Objetivo: Fornecer dados preliminares sobre o desenvolvimento sexual das fêmeas de Psammobatis extenta (Garman, 1913), procedentes da frota pesqueira sediada no Terminal de Pesca de Santos, São Paulo, relacionando observações anatômicas e morfométricas ao grau de desenvolvimento sexual dos indivíduos observados. Material e Método: Estudos preliminares sobre o desenvolvimento sexual desses animais foram realizados com 139 fêmeas descartadas pelos pescadores por não apresentarem valor comercial. As coletas abrangeram exemplares dos litorais de São Paulo, Paraná e Santa Catarina. As amostras foram morfometradas e dissecadas, a fim de se evidenciar o aparelho reprodutor. Resultados: O aparelho reprodutor de Psammobatis extenta está constituído por órgãos pares como os ovários, ovidutos, glândulas nidamentárias e uma cloaca. Dois tipos diferentes de ovários foram encontrados: com ovócitos pequenos de coloração esbranquiçada, considerados imaturos e com ovócitos grandes e amarelados, considerados maduros. A atividade vitelogênica máxima estava presente em $29,4 \%$ das amostras estudadas. Conclusões: A maturidade sexual está relacionada ao tamanho das fêmeas de Psammobatis extenta, porém, outras informações anatômicas, morfológicas e ecológicas devem ser consideradas em futuros estudos sobre esses animais, especialmente do aparelho reprodutor, visando esclarecer o seu nível de correlação com os dois primeiros fatores.

Palavras-chave: Sistema urogenital. Anatomia. Psammobatis extenta. Raias.

\footnotetext{
'Biólogo. Mestre em Anatomia dos Animais Domésticos e Silvestres pela FMVZ/USP

${ }^{2}$ Biólogo do Museu de Zoologia da USP

${ }^{3}$ Professora Doutora do Departamento de Cirurgia da FMVZ/USP. CRMV-SP 1445

*Apresentado em forma de painel no CONGRESSO BRASILEIRO DE MEDICINA VETERINÁRIA, 30., 2003, Manaus
} 


\section{Introdução}

As raias formam um grupo representativo da Classe Chondrichthyes, apresentando cerca de 456 espécies. ${ }^{1}$ A Ordem Rajiformes é a maior da Classe, com aproximadamente 237 espécies, e a Psammobatis extenta (Garman, 1913) é um dos seus integrantes. Exemplares desse gênero são comuns às costas Sudeste do Atlântico e do Pacífico, sendo esses animais endêmicos da América do Sul. ${ }^{2}$

Estudos sobre alimentação e ciclo reprodutivo foram realizados com animais amostrados na costa Norte do Estado de São Paulo. ${ }^{3}$ Todavia, não existem muitas informações sobre os exemplares procedentes da frota de pesca comercial, sediada no Terminal de Pesca de Santos, São Paulo, que abrange coletas do Sul do Estado do Rio de Janeiro até o Norte do Estado de Santa Catarina.

O presente estudo pretende fornecer dados preliminares sobre o desenvolvimento sexual das fêmeas de Psammobatis extenta procedentes da frota pesqueira sediada no Terminal de Pesca de Santos, relacionando observações anatômicas e morfométricas ao grau de desenvolvimento sexual dos indivíduos observados.

\section{Material e Método}

Foram analisadas 139 fềmeas de Psammobatis extenta descartadas pelos pescadores por não apresentarem valor comercial. Foram amostrados exemplares dos litorais de São Paulo, Paraná e Santa Catarina (no segundo semestre de 2001) e, para sua identificação utilizou-se a chave de Paragó ${ }^{4}$ (2001). Os exemplares foram dissecados ventralmente, incisando-se a linha Alba em sentido crânio-caudal. Dessa forma, a musculatura abdominal pôde ser visualizada e, em seguida, rebatida em direção lateral, a fim de alcançar-se a cavidade celomática e os órgãos abdominais. Para melhor visualização do aparelho reprodutor, o estômago e parte do intestino foram removidos, assim como os lobos do fígado. As medidas morfométricas, como comprimento total (CT) e largura do disco (LD), foram anotadas em milímetros e o peso foi registrado em gramas. $\mathrm{O}$ material analisado foi posteriormente fixado e estocado em solução aquosa de formaldeído a $10 \%$, e depositado no Núcleo de Pesquisa e Estudos em Chondrichthyes (NUPEC).

Para a presente pesquisa utilizou-se a observação macroscópica dos órgãos genitais e o comprimento total dos animais, cujas informações estão registradas na Tabela 1.

Tabela 1 - Porcentagem de fêmeas com atividade vitelogênica pelo comprimento total

\begin{tabular}{ccc}
\hline Comprimento total da raia $(\mathbf{m m})$ & Atividade vitelogênica (\%) & Observações \\
\hline $155-164$ & 0 & 2 \\
$165-174$ & 0 & 3 \\
$175-184$ & 0 & 4 \\
$185-194$ & 0 & 8 \\
$195-204$ & 16,7 & 6 \\
$205-214$ & 14,2 & 7 \\
$215-224$ & 0 & 7 \\
$225-234$ & 26,7 & 15 \\
$235-244$ & 54,5 & 11 \\
$245-254$ & 71,4 & 14 \\
$255-264$ & 95,2 & 21 \\
$265-274$ & 100,0 & 16 \\
$275-284$ & 100,0 & 14 \\
$285-294$ & 100,0 & 8 \\
$295-304$ & 100,0 & 2 \\
\hline $305-314$ & 100,0 & 1 \\
\hline
\end{tabular}


CASAS, A. L. S.; CUNHA, C. M.; MARIANA, A. N. B. Relação entre o comprimento total e o desenvolvimento sexual em fêmeas de Psammobatis extenta. Relationship between total length and sexual development in Psammobatis extenta females. Relación entre la largura total y el desarrollo sexual de las hembras del Psammobatis extenta. Rev. Educ. Contin. CRMV-SP/ Contin. Educ. J. CRMV-SP, São Paulo, v. 8, n. 1, p. 77-81, 2005.

\section{Resultados e Discussão}

Pôde-se observar, na presente amostragem, que o aparelho reprodutor de Psammobatis extenta é constituído por três estruturas pares: ovários, ovidutos, glândulas nidamentárias e uma cloaca. Os ovários estão localizados lateralmente ao esôfago, na porção cranial da cavidade celomática e apresentam dois tipos de variação: com pequenos ovócitos de coloração esbranquiçada ou grandes ovócitos de coloração amarelada com atividade vitelogênica.

Por falta de dados sobre o aparelho reprodutor desses animais tomou-se por base os achados de Gilbert $^{5}$ (1986) para tubarões do Gênero Squallus, cuja aparência dos ovários está estreitamente relacionada com o grau de maturação sexual dos indivíduos, sendo que fêmeas imaturas (Figura 1) apresentam ovas pequenas e macias, enquanto as maduras revelaram grandes ovas bem desenvolvidas. Assim, as fêmeas de Psammobatis extenta que apresentaram atividade vitelogênica foram consideradas sexualmente maduras. Nos 139 exemplares examinados encontraram-se dois extremos: $41(29,4 \%)$ animais tinham comprimento total entre 265 a $314 \mathrm{~mm}$ e apresentaram ovócitos amarelos em atividade vitelogênica máxima; enquanto que $17(12,2 \%)$ apresentaram comprimento total de 155 a $194 \mathrm{~mm}$, sem nenhuma atividade vitelogênica; nas outras $81(58,2 \%)$ amostras com comprimento total de 195 a $264 \mathrm{~mm}$ observou-se atividade vitelogênica variada. Todavia, o que chama a atenção é que nos grupos de 225 a 264 mm (43,8\%), a atividade vitelogênica cresce conforme o aumento do comprimento total, em uma proporção aproximada de $20 \%$ para cada $10 \mathrm{~mm}$. Porém, em 13 espécimes de 195 a $214 \mathrm{~mm}(9,3 \%)$ de comprimento total, encontrou-se atividade vitelogênica, embora pequena; e em 7 (5\%) amostras, mesmo com comprimento superior a este $(215$ a $224 \mathrm{~mm})$, a atividade vitelogênica foi nula.

Os animais foram agrupados levando-se em conta as medidas com intervalos de $10 \mathrm{~mm}$.

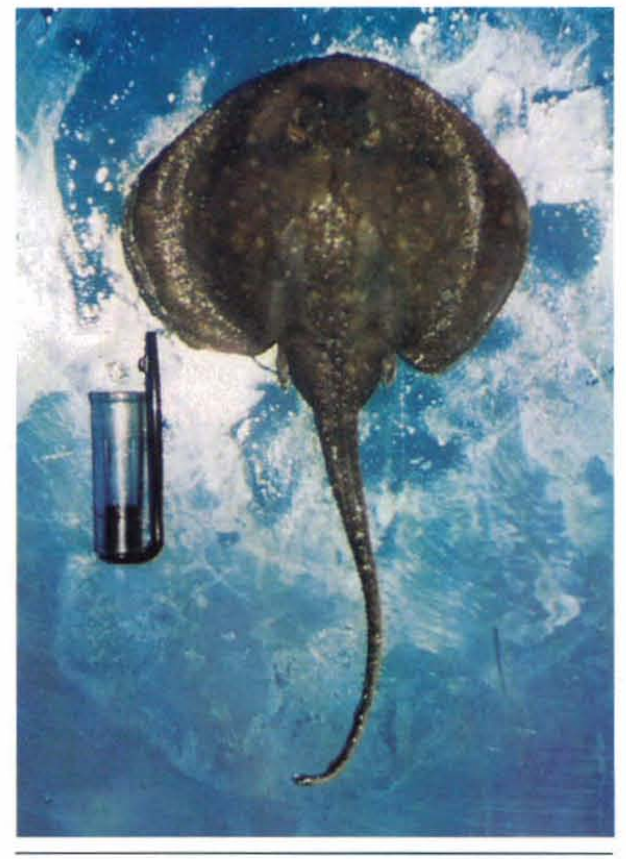

Figura 1 - Raia imatura

\section{Conclusões}

O estudo da anatomia do aparelho reprodutor das fêmeas de Psammobatis extenta ajuda a esclarecer o seu nível de desenvolvimento sexual, que pode ser diferenciado por dois tipos de ovário: ovário imaturo com ovócitos esbranquiçados e pequenos e ovário maduro em atividade vitelogênica com ovócitos amarelados e grandes. A maturidade dos ovários relaciona-se ao tamanho dos animais. Contudo, essa relação não pode ser considerada de maneira absoluta e direta, portanto, observações em um grupo maior com mais detalhes e outras informações, inclusive ecológicas, são necessárias para a complementação do presente estudo.

\section{Agradecimentos}

Ao Professor Manoel Mateus Bueno Gonzalez, presidente do Núcleo de Pesquisa e Estudos em Chondrichthyes (NUPEC), por ter gentilmente cedido o material para a elaboração do presente trabalho. 
CASAS, A. L. S.; CUNHA, C. M.; MARIANA, A. N. B. Relação entre o comprimento total e o desenvolvimento sexual em fêmeas de Psammobatis extenta. Relationship between total length and sexual development in Psammobatis extenta females. Relación entre la largura total y el desarrollo sexual de las hembras del Psammobatis extenta. Rev. Educ. Contin. CRMV-SP/ Contin. Educ. J. CRMV-SP, São Paulo, v. 8, n. 1, p. 77-81, 2005.

\section{Abstract}

Objectives: To present preliminary data on the sexual development of Psammobatis extenta females (Garman, 1913) proceeding from the fishing fleet harbored in the Fishing Terminal in Santos, São Paulo, Brazil, correlating anatomical and morphometric observations to the degree of sexual development of the specimens studied. Material and Method: Preliminary studies on the sexual development of these animals were conducted in 139 females discarded by fishermen for lack of commercial value. The sampling included specimens from the coastal areas of São Paulo, Paraná and Santa Catarina, Brazil. Samples were morphometrically analyzed and dissected for study of the reproductive system. Results: The Psammobatis extenta reproductive system consists of paired organs, such as ovaries, oviducts, and nidamentary glands, and a cloaca. Two different types of ovaries were identified: one with small whitish oocytes, considered immature, and one with large yellowish oocytes, considered mature. Maximum vitelogenic activity was present in 29,4\% of the samples studied. Conclusions: Sexual maturity is related to the size of the Psammobatis extenta females, but other anatomical, morphological and ecological information should be considered in future studies on such animals, particularly on their reproductive system, in order to clarify the level of correlation between these two factors.

Keywords: Urogenital system. Anatomy. Psammobatis extenta. Skates (fish).

\section{Resumen}

Objetivo: Proveer datos preliminares sobre el desarrollo sexual de las hembras de Psammobatis extenta (Garman 1913) procedentes de la flota pesquera con sede en el puerto pesquero de Santos, São Paulo, Brasil, relacionando observaciones anatómicas y morfométricas al grado de desarrollo sexual de los ejemplares observados. Material y Método: Estudios preliminares sobre el desarrollo sexual de estos animales se realizaron en 139 hembras descartadas por los pescadores por no presentar valor comercial. Las colectas abarcaron ejemplares de los litorales de los estados brasileños de São Paulo, Paraná y Santa Catarina. Se tomaron las características morfométricas y se disecaron los ejemplares, para evidenciar el aparato reproductor. Resultados: El aparato reproductor de Psammobatis extenta está constituido por órganos pares como los ovarios, oviductos, glándulas nidamentales y una cloaca. Se encontraron dos tipos diferentes de ovarios: con ovócitos pequeños de coloración blanquecina considerados inmaduros y con ovócitos grandes y amarillos considerados maduros. La actividad vitelogénica máxima estaba presente en un 29,4\% de las muestras estudiadas. Conclusiones: La madurez sexual se relaciona al tamaño de las hembras de Psammobatis extenta, aunque otras informaciones anatómicas, morfológicas y ecológicas deben ser consideradas en futuros estudios sobre esos animales, especialmente del aparato reproductor, procurando descubrir el nivel de correlación del mismo entre esos dos factores.

Palabras-clave: Aparato urogenital. Anatomía. Psammobatis extenta. Rayas. 


\section{Referências}

1. Nelson, J. S. Fishes of the world. New York: John Wiley, 1994. $600 \mathrm{p}$.

2. Carvalho, M. R.; Figueiredo, J. L. Psammobatis extenta (Garman, 1913): a senior synonym of Psammobatis glandissimilis (McEachran, 1983), (Chondrichthyes, Rajidae). Copeia, v. 4, p. 10291033, 1994.

3. Muto, E. Y.; SoARes, L. S. H.; GoItein, R. Food resource utilization of $R$. agassizii and $P$. extenta. Revista Brasileira de Biologia, v. 61, p. 217-238, 2000.
4. PARAGó, L. D. P. Contribuição à taxonomia do gênero Psammobatis, Gunther, 1870, (Chondrichthyes, Rajidae): caracterização das espécies do subgrupo I de McEachran (1983) com base em padrões de coloração e espinulação. Rio de Janeiro, 2001. 52 f. Dissertação (Mestrado em Zoologia)- Universidade Federal do Rio de Janeiro, Rio de Janeiro, 2001.

5. Gilbert, S. G. Pictorial anatomy of the dogfish. Seattle: University of Washington Press, 1986. $59 \mathrm{p}$. 